\title{
Assessment of circulating tumor cells in peripheral blood using flow cytometry in patients with surgery for colorectal cancer - review
}

\author{
Ana-Maria Mușină ${ }^{1,2}$, Ionuț Huțanu ${ }^{1,2^{*}}$, Mihaela Zlei ${ }^{1,3}$, Mădălina Ștefan ${ }^{3}$, \\ Mihaela Mentel ${ }^{1,3}$, Maria-Gabriela Aniței ${ }^{1,2}$, Bogdan Filipp ${ }^{1,2}$, Dragoș Viorel \\ Scripcariu ${ }^{1,2^{*}}$, Mihaela-Mădălina Gavrilescu ${ }^{1,2}$, Andrian Panuțat, ${ }^{1,2}$, Mihaela Buna- \\ Arvinte $^{1,2}$, Iulian Radu ${ }^{1,2}$, Viorel Scripcariu ${ }^{1,2}$ \\ 1. Department of Surgery, University of Medicine and Pharmacy Grigore T. Popa Iasi, Romania \\ 2. Regional Institute of Oncology, I-st Surgical Unit, Iasi, Romania \\ 3. Center for fundamental research and experimental developing in translational medicine Transcend, \\ Iasi, Romania
}

\begin{abstract}
Introduction: Colorectal cancer (CRC) is the third most common neoplasia in the world. Circulating tumor cells (CTC) have a prognostic value and can be useful in monitoring solid neoplasia. Only one method for CTC identification has received the approval and this is the CellSearch ${ }^{\circledR}$ system based on the immunomagnetic separation. Multiple markers are used in CTC identification, as epithelial markers and cytokeratines. CTC identification in peripheral blood is associated with a worse prognostic and reduced free survival in CRC. Material and methods: We performed a systematic search in PubMed database for articles that reports the circulating tumor cells in CRC until July 2019. We selected studies in English and French and the main words used for search were 'circulating tumor cells', 'colorectal cancer', 'colon cancer', 'rectal cancer', 'flow cytometry', 'peripheral blood'. We included studies with more than 10 patients, where samples were collected from the blood in relation with surgery and flow cytometry was used as analyzing technique. Results: We included 7 studies in final analysis, that showed in flow cytometry analysis a cut-off value of CTC that can vary from 2-4 CTC/ $7.5 \mathrm{ml}$ peripheral blood with a sensitivity of 50.8\% and specificity of $95 \%$. Patients with positive CTC were associated with higher T stage and positive lymph nodes, with a worse overall survival (OS) and disease free survival (DFS) comparing with negative patients. Conclusion: CTC are considered to be a prognostic factor who needs more validation studies in order to be included in the clinical practice.
\end{abstract}

Keywords: colorectal cancer, flow cytometry, circulating tumor cells Received: 29 th June 2020; Accepted: 11 ${ }^{\text {th }}$ September 2020; Published: $25^{\text {th }}$ September 2020

\footnotetext{
* Corresponding authors: Ionut Huțanu, University of Medicine and Pharmacy Grigore T. Popa Iasi, Romania. E-mail: hionut65@gmail.com. Dragos Viorel Scripcariu, University of Medicine and Pharmacy Grigore T. Popa Iasi, Romania. E-mail: dscripcariu@gmail.com.
} 


\section{Introduction}

Colorectal cancer (CRC) is the third most common neoplasia in the world (1) and the risk of developing a colorectal carcinoma during one's lifetime is $>5 \%$ in general population due to lack of complete curative results of current therapies (2). Prognostic in colorectal cancer is associated with circulating tumor cells (CTC) that are proved to be a marker for metastasis and penetration available for solid tumor (3). Liquid biopsy refers to the use of free circulating tumor DNA and cells, and is consider useful in monitoring multiple types of neoplasia $(4,5)$. Detection of free circulating cancer cells in the blood of patients with CRC can be used as a prognostic tool and a mode for colorectal cancer staging (6), the presence of CTC being associated with a poor prognosis (7). Identification of CTC in blood of patients with CRC is significantly associated with aggressive disease free progression $(p<0.001)$ and the persistence of CTC reduces disease survival (8), thus being considered an independent prognostic factor (9). Related to surgical resection, the presence of CTC in the peripheral blood for at least 24 hours postoperatively, is considered to be an independent prognostic marker of recurrence especially in stage III CRC $(10,11)$. No-touch surgical resection technique based on primary ligation of the lympho-vascular pedicle applied in CRC is used in order to reduce blood spreading of CTC (12) while the laparoscopic approach is consider not to have any influence on CTC number (13). Identification of CTC as a prognostic marker has proven useful for other multiple neoplasia such as breast, prostate, gastric and lung cancer (14-16). Multiple techniques such as reverse transcription polymerase chain reaction (RTPCR) and immunocytochemistry (17) are used for CTC identification with a variable specificity and sensitivity. The first standardized system approved by The Food and Drug Administra- tion (FDA) in the USA for CTC detection is the CellSearch ${ }^{\circledR}$ system based on a semiautomatic immunomagnetic method for identification. In a meta-analysis CellSearch ${ }^{\circledR}$ system proved to have a prognostic utility with a significant value of CTC detected in metastatic CRC patients compared with non-metastatic ones $(p<0.01)$ (18). There are two-types of markers that are used in order to identify CTC in CRC: epithelial specific markers such as epithelial cells adhesion molecule (EpCAM) and cytokeratines 18, 19, 20 and specific markers such as carcinoembryonic antigen (CEA) (1). Flow-cytometry is another technique used to identify CTC (19) and a protocol for detection and enumeration of circulating endothelial and progenitor cells in human blood was published (20) and it presented a technique that offers the advantage of morphologically examining targeted cells. CTC are a prognostic marker for CRC patients treated with chemotherapy and can be considered to be a predictive marker for the response to oncologic treatment (21). In rectal cancer, CTC can predict response to neoadjuvant radio-chemotherapy, with a significant reduction of CTC number after treatment in responders compared to non-responders (22). Due to the diversity of methods in identifying CTC, in order for it to become a powerful prognostic tool, a standardization in the detecting and reporting of the number of CTC is necessary and it should come about through large-scale multicenter validation studies (23).

Although the traditional staging in $\mathrm{CRC}$ has a prognostic value in most of the cases, there are many patients in whom tumor behavior does not overlap with classical staging methods, this data suggesting that other prognostic factors, such as tumor microenvironment, intestinal microbiota, immune infiltrate and CTC, should be evaluated. The purpose of our study is to evaluate the feasibility of detection of CTC in patients with surgery for CRC by using the flow cytometry 
method and to show the necessity of a standardized protocol for clinical implementation.

\section{Material and methods}

\section{Search strategy}

We performed a systematic search for relevant studies in PUBMED database with no time restriction up until July 2019. We were searching for articles that report the circulating tumor cells in CRC. We only selected studies written in English and French and the main words used for the search were 'circulating tumor cells', 'colorectal cancer', 'colon cancer', 'rectal cancer', 'flow cytometry', 'peripheral blood' linked with Boolean operators AND. Two independent researchers (AMM and IH) performed the systematic search. We used the recommendations from the preferred reporting items for systematic reviews and metaanalyses (PRISMA) guidelines (24) that helped us in study selection in order to evaluate the quality of items from the included articles.

\section{Inclusion criteria}

In order to be included in our review, all the eligible studies had to fulfill the following criteria: 1) studies with more than 10 patients included in the series; 2) the samples had to be collected from the peripheral blood of patients; 3 ) flow cytometry had to be the used as the analyzing technique; 4) samples had to be collected in relation to surgical stages.

\section{Exclusion criteria}

Studies were excluded from the review if: 1) the samples were used from other sources than peripheral blood (peritoneal cavity, bone marrow, lymph nodes, solid tumor); 2) the analyzing technique was different than flow cytometry; 3 ) the studies analyzed less than 10 patients; 4) the sample collection had no association to the surgery undergone by patients; 5) there were multi- ples types of cancer included in the same article. All data represented by abstract meetings were excluded due to the lack of sufficient information they were presenting.

\section{Quality assessment of the articles}

The quality of the studies was assessed by evaluating the methodological quality of each article, based on the Cochrane Handbook for Systemic Review of intervention and an assessment list. The two researchers before mentioned independently assessed the evaluation of each article. All studies were evaluated in order to analyze: the number of cases, consecutive series and prospective studies, flow cytometry technique and antibodies description, blood sampling and collection time, the collecting of samples' relation to surgery, tumor stage and complete results reported. Each study received a score of 1 to 9 (Table 1, Figure 1). The performance of each study was measured based on the detection rate, the sensibility and accuracy of the method used for CTC identification and the estimated survival rates with a $95 \%$ confidence interval. We decided to exclude the case series and studies with less than 10 patients included because we considered this limit necessary in achieving the learning curve in the implementation of the flow cytometry protocol. Since the number of selected studies is limited, we decided to consider the 10 patients limit the cut-off.

\section{Data extraction}

All data were extracted only from the original studies published, all the review and metaanalysis being excluded. We reviewed all the included studies and extracted the interest information on a preformed database. We extracted the first author and year of publication, country, patient number, sampling time in relation to surgery, situs collection of the blood and blood volume, cancer type and staging according to Dukes or Union for International Cancer Control (UICC), 
Table 1. Quality assessment of the studies evaluated by the authors

\begin{tabular}{|c|c|c|c|c|c|c|c|c|c|}
\hline Author & $\begin{array}{c}\text { Patients } \\
>10\end{array}$ & $\begin{array}{c}\text { Con- } \\
\text { secutive } \\
\text { Series }\end{array}$ & $\begin{array}{c}\text { Pro- } \\
\text { spective } \\
\text { Studies }\end{array}$ & $\begin{array}{c}\text { Blood } \\
\text { sam- } \\
\text { ples }\end{array}$ & $\begin{array}{c}\text { Col- } \\
\text { lection } \\
\text { time }\end{array}$ & $\begin{array}{c}\text { Flow-cy- } \\
\text { tometry } \\
\text { technique } \\
\text { details }\end{array}$ & $\begin{array}{c}\text { Markers } \\
\text { used re- } \\
\text { ported }\end{array}$ & $\begin{array}{l}\text { Sur- } \\
\text { gery } \\
\text { relat- } \\
\text { ed }\end{array}$ & $\begin{array}{l}\text { Com- } \\
\text { plete } \\
\text { results }\end{array}$ \\
\hline $\begin{array}{l}\text { Fang et al. } \\
(24)\end{array}$ & + & + & + & + & + & + & + & + & + \\
\hline $\begin{array}{l}\text { Galizzia et } \\
\text { al. (25) }\end{array}$ & + & + & + & + & + & + & + & + & + \\
\hline $\begin{array}{l}\text { Tralhao et } \\
\text { al. (26) }\end{array}$ & + & + & + & + & + & + & + & + & - \\
\hline $\begin{array}{l}\text { Cohen et } \\
\text { al. (27) }\end{array}$ & + & + & + & + & + & + & + & + & + \\
\hline $\begin{array}{l}\text { Tseng et } \\
\text { al. (28) }\end{array}$ & + & + & + & + & + & + & + & + & + \\
\hline $\begin{array}{l}\text { Tsavellas } \\
\text { et al. (29) }\end{array}$ & + & + & - & + & + & + & + & + & + \\
\hline $\begin{array}{l}\text { Bahnassy } \\
\text { et al. (30) }\end{array}$ & + & + & + & + & + & + & + & + & + \\
\hline
\end{tabular}

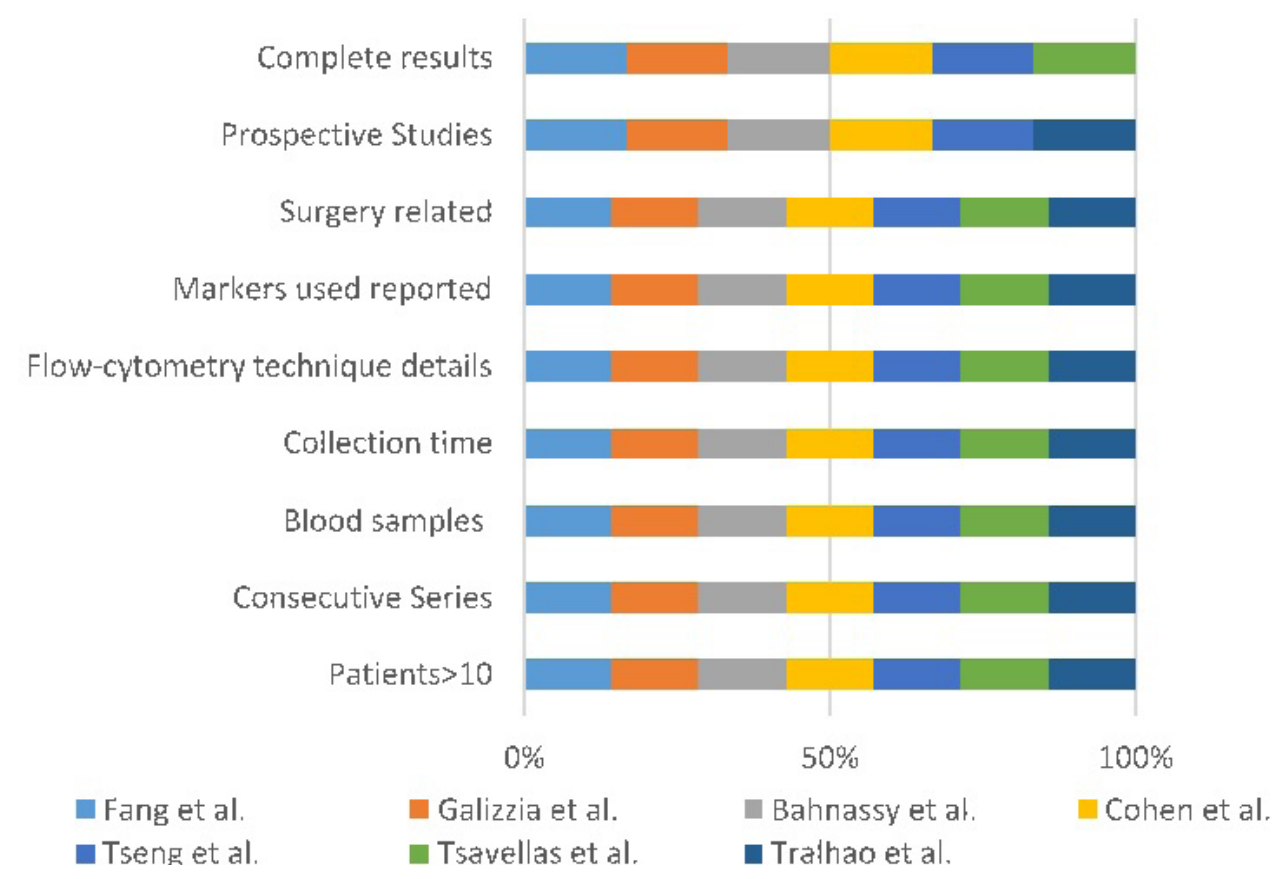

Fig.1. Quality of the studies performed by the authors 
type of surgery, tumor localization, patient age, identified markers, detection rate, number of CTC and cut-off for CTC, follow up median, diagnostic specificity and outcomes.

\section{Results}

In PubMed database, we recorded a number of 1833 items. Based on the title and abstracts we excluded 1328 articles. We took 505 articles into evaluation out of which we selected 32 articles. Out of those we excluded another 25 articles either because the sampling was not in relation to the surgical moment or the analysis was performed for a precursor of circulating tumor cells. In the end we evaluated seven articles to be included in this study.

\section{Study characteristics (Table 2)}

A total number of 562 patients were evaluated in our included articles (25-31) and associated 62 case control patients (25-27). Publication time was from 2006 to July 31-st 2019 with no more than one study published each year. Most of the articles evaluated a small series of patients (25-27,29-31) and only one article evaluated more than 100 patients (28). In two of the articles a group control was selected in order to compare the analysis $(25,27)$. Median age of the patients included was 64 with a range between 21-91 years of age. In only two of the studies $(25,29)$ was the histopathologic type mentioned (adenocarcinoma $=115$, mucinous $=14$ ). The samples were collected from peripheral blood and in only one study is the situs puncture referred to as the antecubital vein (30). Four of the studies used only one blood sample that was collected in relation to the moment of surgery $(25,28,30,31)$ : before surgery $(25,30)$, during surgery $(31)$ and after surgery (28). In three studies the samples were collected thusly: two blood samples, before surgery and one month after surgical resection (29), three blood samples, at surgical incision, after tumor resection and at the end of the surgical intervention (26) and three samples during surgery at every one minute interval (27). The median sample blood size was $12.5 \mathrm{ml}$ with a range between $7.5-84 \mathrm{ml}(25-30)$ and in one study the size is not mentioned (31). Tumor localization was mentioned in five out of the seven studies $(25,26,28,29,31)$ and was represented by rectum $(n=168,29.89 \%)$ and colon $(n=139$, $24.73 \%)$, out of the latter left colon $(n=49$, $35.25 \%)$ and right colon $(n=42,30.21 \%)$. In two of the studies the tumor site was not specified so the patients were considered with colorectal localization $(n=193,34.34 \%)$ associated with liver metastasis $(n=16,2.84 \%)(27,30)$. Surgical treatment was applied for all cases included in our studies but in only two of the articles $(26,28)$ are the surgical procedures described (Table 2). Tumor stage was reported in all cases using TNM or Dukes classification and was as follows: stage I $(n=25)$, stage II $(n=62)$, stage III $(n=158)$, stage IV $(n=124)$ (Table 3).

\section{Markers used in CTC identification using flow cytometry (Table 3)}

All studies (25-31) used CD45 as a marker in flow cytometry analysis. Two of the studies $(25,27)$ used CD45, EpCAM and cytokeratines (CK) markers in order to identify CTC, and positive CTC were considered to be cells $\mathrm{CK}+$ and CD45-. One study (31) used epidermal growth factor marker (EGFR) and nucleic acid stain in association with $\mathrm{CK}$ and $\mathrm{CD} 45$, positive CTC being considered $\mathrm{CD} 45-/ \mathrm{CK}+/$ nucleic acid dye+/EGFR+. Tseng et al. (30) defined the positive CTC as ESA+ (epithelium specific antigen)/ CD45-. One study (28) used multiple markers in analysis and considered as positive CTC the CD133+, CD54+, CD44+, CD45- cells. Galizia et al. (29) associates to the EpCAM and CD45 analysis, CD326, and considered CTC positive as EpCAM/CD326+ and CD45-. 


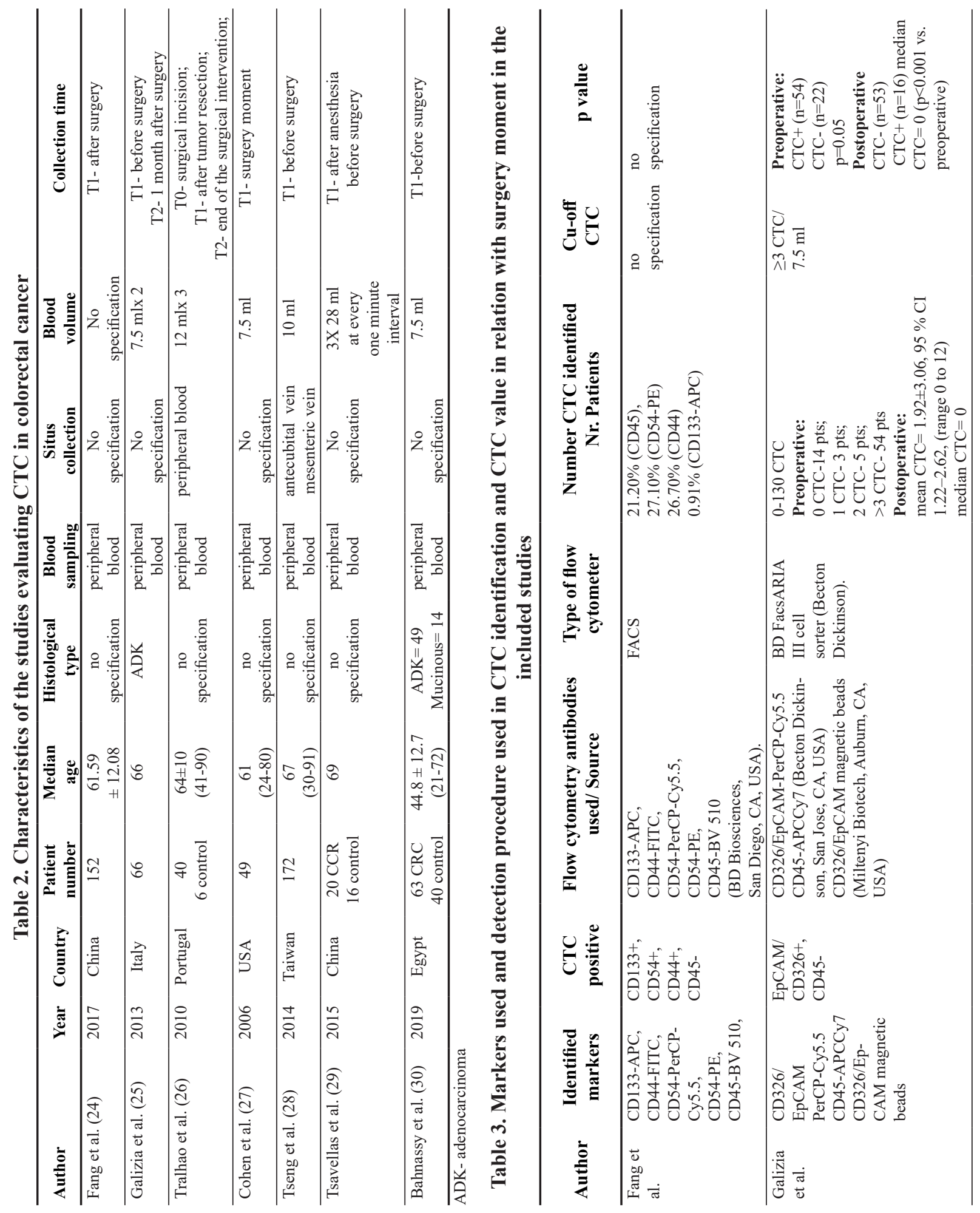




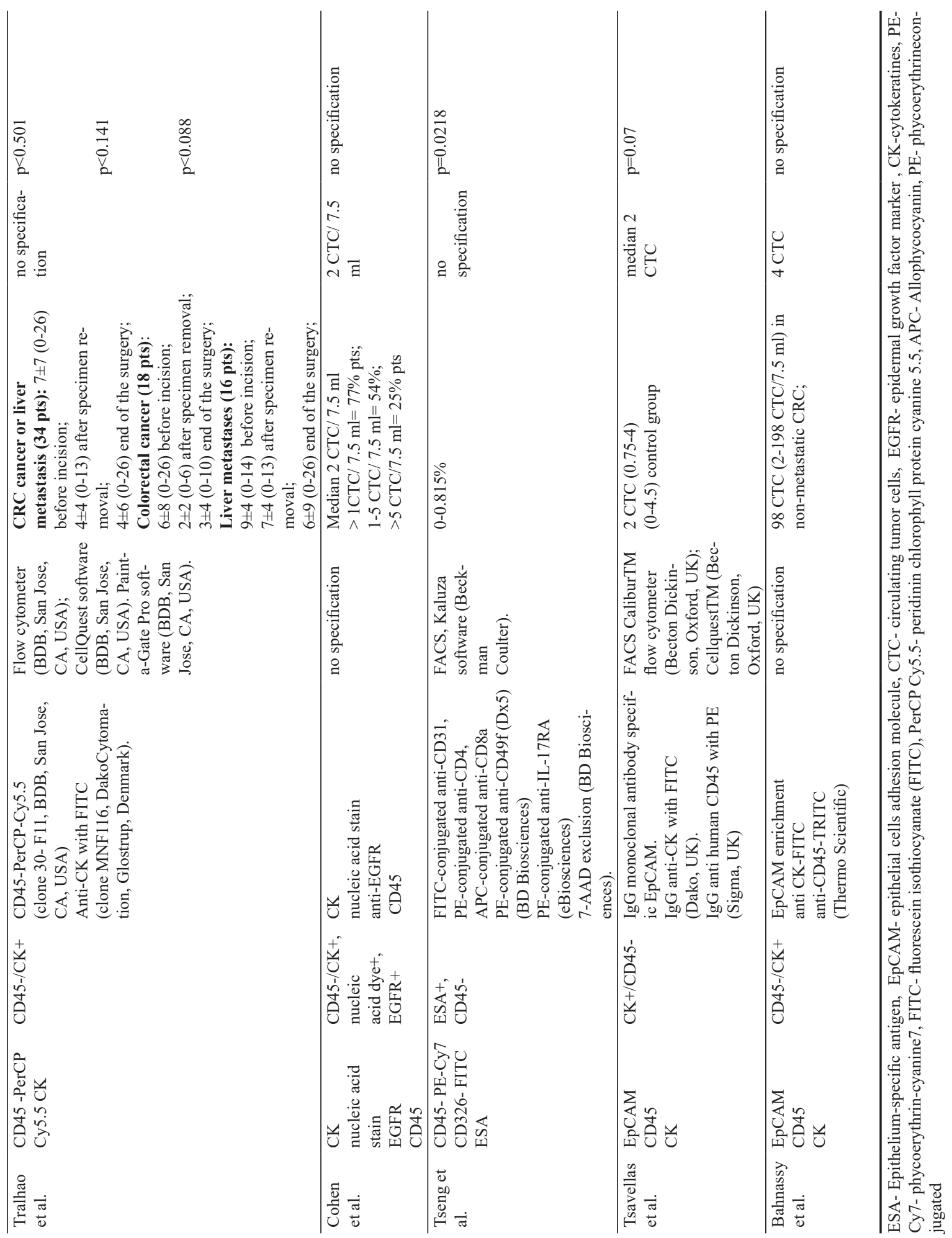




\section{Diagnostic procedure for CTC identification and CTC value (Table 3)}

All studies (25-31) used flow-cytometry as the identification technique, with different types of flow cytometers (26-30). In one study Kaluza software was used for analysis (30), in another two studies, CellQuest $(26,27)$ and Paint-aGate Pro software (26) while in another four studies $(25,27-29,31)$ the analysis software was not specified. The number of CTC identified are reported in all studies and this value varies in relation to the surgical resection $(26,29)$ (Table 3). The cut-off value for CTC is reported in four studies, with a value of $2 \mathrm{CTC} / 7.5 \mathrm{ml}$ blood (27,31), $\geq 3 \mathrm{CTC} / 7.5 \mathrm{ml}$ blood (29) and 4 CTC (25). In three studies $(26,28,30)$ the cut-off value is not specified. Bahnassy et al. (25) reports a sensitivity of $50.8 \%$ of flow cytometry in detecting CTC ( $\geq 4$ CTC/7.5 ml blood) with a $96.3 \%$ specificity and $76.2 \%$ accuracy associated with a positive detection rate (CTC $\mathrm{CK}+/ \mathrm{CD} 45-)$ of $50.8 \%$. One study (31) reports a sensitivity of $50 \%$ for the same method and another three studies (27-29) report a 95\% specificity.

\section{Correlation of CTC and TNM stage (Table 4)}

Only three studies $(25,29,30)$ showed a correlation of CTC and TNM stage.

Galizia et al. (29) report that CTC positive ( $\geq 3$ CTC ) patients were associated with advanced $\mathrm{T}$ stage $(p=0.001), M$ stage $(p=0.005)$ and Dukes stage $(p=0.001)$. Patients in early Dukes stages associated with normal postoperative CTC levels have a significant lower risk of tumor relapse compared to advanced Dukes stages and high postoperative CTC levels patients $(\mathrm{p}<0.001)$.

Bahnassy et al. (25) show that patients with positive CTC are associated with a higher $\mathrm{T}$ stage (30 CTC positive patients out of 53 patients, $\mathrm{p}=0.034)$, stage III TNM (21 CTC positive patients out of 30 patients, $\mathrm{p}=0.004)$ and positive lymph nodes stage (20 CTC positive patients out of 28 patients, $\mathrm{p}=0.005$ ).
Tseng et al. report that a higher number of CTC in mesenteric blood was identified in stage II CRC compared to stage I $(p=0.52)$, III $(p=0.023)$ and IV $(p=0.035)(30)$.

\section{Results of each studies and impact of CTC in patient's survival}

Fang et al. (28) report that patients who received both primary tumor and liver metastasis surgical resection had a better survival than those who received only primary tumor resection (3year OS, 70.8\%, 43.8\%, and 4.5\%, respectively; $\mathrm{p}<0.001)$. Patients with a high expression of CD133+CD54+ $(p<0.001)$, CD133-CD54+ $(p=0.004)$ and CD133+CD44+CD54+ $(p=0.003)$ CTC had a worse overall survival compared to patients with low expression. In multivariate analysis, CD133+CD44+CD54+ subpopulations of CTC $(\mathrm{HR}=6.459 ; 95 \% \mathrm{CI}=1.461-28.558$; $\mathrm{p}=0.014$ ) were considered an independent prognostic factor for patients with CRC. High value of CD133+CD44+CD54+ subpopulation was associated with a worse survival in patients without surgical resection of liver metastasis than in patients with low expression (3 year OS, 9.1\% vs. 57.1\%; p<0.001) (28).

When analyzing the number of CTC in patients with colorectal cancer associated with liver metastasis, CRC or liver metastasis group alone, the number of CTC varies in relation to the surgical moment (before incision, specimen removal or end of surgery) but without statistical signification $(\mathrm{p}=0.501, \mathrm{p}=0.141$, respectively $\mathrm{p}=0.088$ ). These results give rise to the question of the role of the "no touch" technique in patients with colorectal cancer and liver metastasis (26).

At a CTC cut-off value $\geq 3$ Galizia et al. (29) report differences between the preoperative CTC positive and negative patients (54 versus 22 patients) with a higher progression free survival in patients with zero to two CTC than in those with $\geq 3$ CTC identified $(p=0.06)$. Preoperative $\geq 3$ CTC were significantly associated with $\mathrm{T}$ 


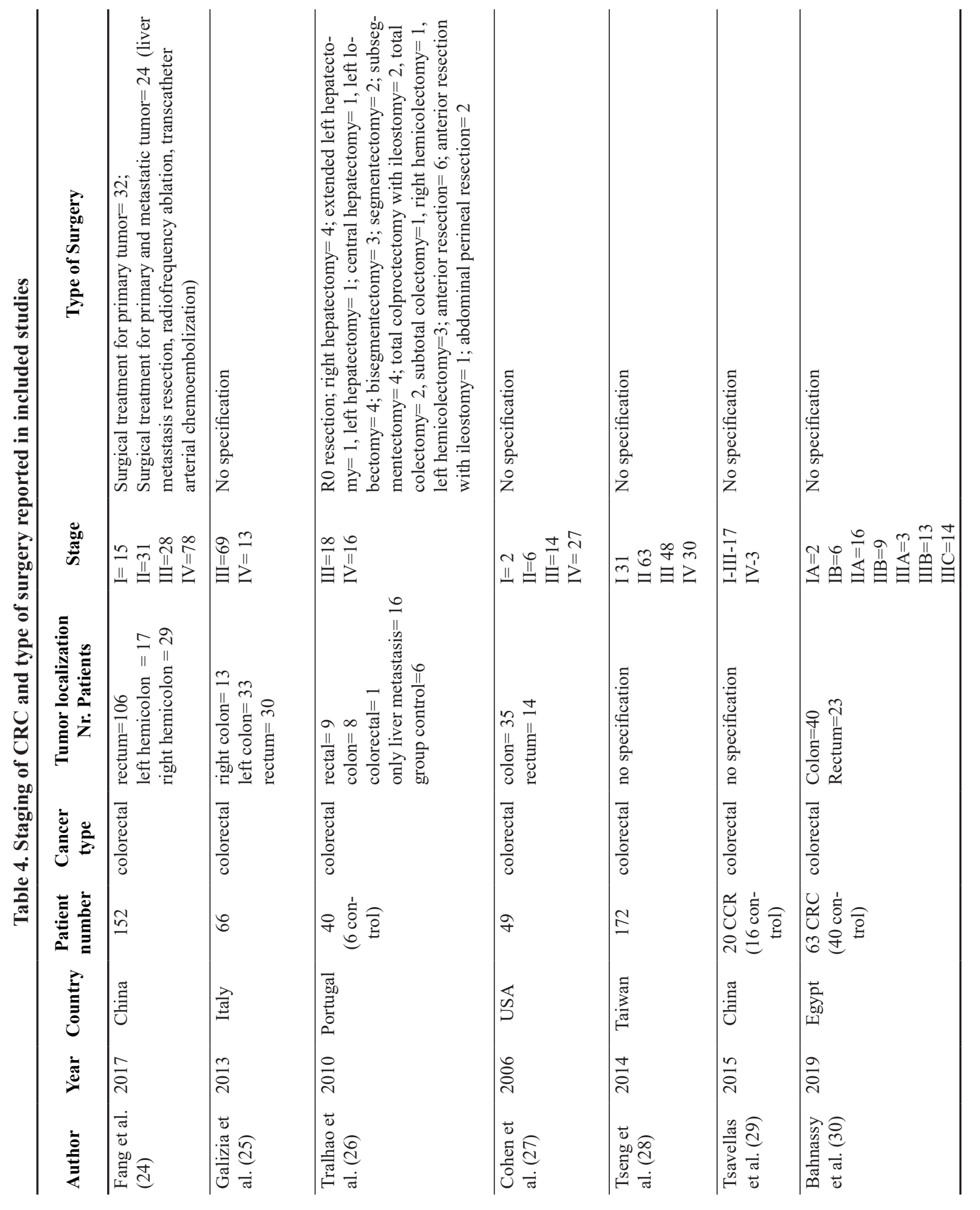


stage $(\mathrm{p}<0.001)$, M stage $(\mathrm{p}<0.005)$, Dukes stage $(p<0.001)$ and CEA serum level $(p<0.02)$ with lower progression free survival in univariate analysis in CTC positive patients with potentially curative surgery $(\mathrm{p}=0.05,47$ positive patients vs. 22 negative patients). Postoperative median CTC is 0 with no cell identified, with significant differences $(\mathrm{p}<0.001)$ in progression free survival (PFS) compared to preoperative levels when analyzing the patients (53 negative vs 16 positive patients). The progression free survival was $89.6 \%$ at one year, $76.1 \%$ at two years and $68.3 \%$ at tree years, with a CTC accuracy of $88.4 \%$ of predicting tumor recurrence. High postoperative CTC levels were correlated with tumor relapse and in multivariate analysis it was the only independent factor correlated with increased tumor recurrence rate $(\mathrm{p}<0.001)$ (29).

Tsavellas et al. (27) report a median of 2 CTC positive (IQR (interquartile range) $=0.75-4$ ) in patients with colorectal cancer, but without significant differences compared to no cancer patients ( $\mathrm{p}=0.07, \mathrm{IQR}=0-4.5)(27)$.

Cohen et al. (31) report that during treatment no significant differences in CTC number was observed in progression compared to no progression patients after the flow cytometry analysis $(+0.6$ cells vs. -1.9 cells, $\mathrm{p}=0.48)$ and time to progression was not predicted by the CTC number (6.6 months for $<2$ CTC, 6 months $\geq 2$ CTC, $\mathrm{p}=0.89$ ) (31).

Patients with $\geq 4$ CTC detected by flow cytometry had a statistically reduced 5 year DFS $(27.5 \%$ vs $100 \%, p=0.001)$ and overall survival $(17.2 \%$ vs $91.7 \%, p=0.001)$ compared to patients CTC negative ( $\leq 4$ cells) (25). In univariate analysis, the CTC number detected by flow cytometry was an independent prognostic factor for both PFS $(p<0.001)$ and OS $(p=0.01)$ but only for PFS in multivariate analysis $(\mathrm{p}<0.001)(25)$.

The number of CTC identified in mesenteric vein was shown to be higher than the number identified in forearm vein $(p=0.0218)$ with a positive correlation of those two $(\mathrm{p}=0.0017)$. Patients with high number of CTC in forearm vein were significantly associated with a high number of CTC in mesenteric vein $(p=0.001)$. Patients with a high number of CTC in mesenteric vein had a significant reduced PFS compared to patients with low CTC number ( $\mathrm{p}=0.0016)$ (30).

\section{Discussion}

Circulating tumor cells are cancer stem cells that can derive from both primary and metastatic tumor and their presence is associated with progression and metastasis. The CTC presents a immunophenotype signature by expression of CD45-/EpCAM+ and an epithelial origin (32). The CTC identification in patients with CRC is possible using different methods: physic analysis that use centrifugation and filtration methods or phenotypic analysis that evaluate the surface markers expression and specific antibodies (by flow cytometry). Morphologic identification uses cytological analysis or markers' identification through immunohistochemistry or immunofluorescence. Molecular biology techniques like in situ hybridization (FISH) perform the ARN analysis and, in association with RT-PCR, can identify specific mutations (33). Immunohistochemistry using monoclonal antibodies in CTC identification has low sensitivity and requires prior tumor cells' enrichment (34).

Flow cytometry presents some advantages when compared to other CTC detection methods. Flow cytometry allows for a higher CTC yield when compared to fluorescent microscopy and ensures an accurate quantification and an imunophenotypic assessment of each cell in the sample.

CTC characterization through flow cytometry associated with gene identification is a noninvasive predictor factor for clinical response to treatment and could guide new therapies and drug development (31). Flow cytometry also allows single-cell analysis and allows inclusion 
and exclusion of different cell populations when their origin is uncertain at any time after sample acquisition (29). The disadvantages of using flow cytometry are represented by the higher costs, the necessity for high technical expertise, the time consuming protocol for sample acquisition and the evaluation of a quantitative expression of receptors that are not well documented in the literature (26). The development of highspeed flow cytometry ensures the acquisition of 20.000 events per second with a reduced time for the study protocol and thus the increasing interest in using this technique for rare events identification such as CTC in CRC (26). Still, the lack of a standardized protocol validated in multicenter prognostic studies for CTC identification in CRC cancer is a limitation on the use of this technique.

Besides CRC, the analysis of CTC proves to be a prognostic marker in breast cancer where patients with $>5 \mathrm{CTC} / 7.5 \mathrm{ml}$ blood have a worse progression free and overall survival $(\mathrm{p}<0.0001)$ than patients with $<5$ CTC (4). Identification of cytokeratin 19 using flow cytometry ensures a CTC detection rate of $86 \%$ in stage IV breast cancer (35). The presence of CTC is considered the first step to metastasis and for patients with curable surgery and $>5 \mathrm{CTC}$, the risk of presenting distant metastasis in the first year is 8 times higher (36). In stage III and IV CRC, the mean number of CTC identified using flow cytometry was $5 \pm 1$ cells/ml for CD133+/CD45- and respectively $29 \pm 3$ cells/ml for CK20+/CD45- that consider CTC identification as a useful biomarker for personalized metastatic risk evaluation (37). Almost $95 \%$ of the colorectal cancers and metastasis with this origin are CK20 positive, which makes cytokeratin a suitable marker in CTC with CRC origin identification (38). In order to predict survival in colorectal cancer, new robust prognostic biomarkers are necessary and clinical trials with specific protocols for CTC identification are initiated (39). When a cut-off $\leq 30 / \mathrm{ml} \mathrm{CTC}$ is established, the OS and PFS are 37.1 and respectively 13.3 months while at $>30 \mathrm{CTC} / \mathrm{ml}$ median OS is 14.9 months and PFS is 5.1 months, with significant differences $(p<0.001)$ in metastatic colorectal cancer (40). For patients undergoing liver resection for metastatic colorectal cancer, CTC identification in central venous blood is associated with patient's prognosis compared to CTC identification in peripheral blood (41). CTC identification in mesenteric blood predicts clinical survival compared to CTC identification in central blood (42). Preoperative search of CTC in non-metastatic CRC is associated with a low number of CTC identified (43). CTC identification can predict progression and distant metastasis even for patients with nonmetastatic colorectal cancer, patients with $\geq 5$ CTC having an 8 times higher risk of developing liver metastasis during the first year post- surgery (44). Identification of $>2$ CTC using immunostaning fluorescence in situ hybridization at three months after surgery in CRC is associated with worse PFS than in patients with $<2$ CTC (45). When detected, perioperative CTC are an independent prognostic factor (46) and when they are associated with lymph node status they allow for patients' classification into high and low-group with impact in treatment management (47).

When comparing open surgery to laparoscopic approach for CRC, the CellSearch ${ }^{\circledR}$ system shows significant differences between these two techniques when both peripheral and portal venous blood was analyzed $(p=0.002)$, with a lower number of CTC being identified during the minimally invasive approach probably because of the medial to lateral approach resection (48). A number of $>2$ CTC can appear in 30\% of patients with CRC and in $57 \%$ of patients with prostate cancer (49) with a detection rate that varies from $4 \%$ to $57 \%$ as reported in a systematic review (17). 
Ongoing trial is evaluating the role of liver resection in colorectal cancer liver metastasis in order to research the role of surgical approach in haematogenous cancer cells dissemination and prognostic value (50). In a metaanalysis it is shown that the CTC positive patients have a significantly increased liver metastatic rate of up to $21 \%$ ( 22 of 203 patients) compared to $8 \%$ (16 of 207 patients) in negative patients $(\mathrm{OR}=6.38, \mathrm{CI}$ 2.67-15.25) (6) and CTC detection is associated with disease progression and poor survival (51). In conclusion, CTC identification is useful and it was proven to have a role in predicting clinical evolution in patients with CRC, a high number of CTC preoperatively or postoperatively being associated with a worse prognostic in terms of overall survival and disease free survival. Studies show that CTC can be considered as an important prognostic marker but in order for it to be included in clinical practice new trials for clinical validation are necessary. Flow cytometry is a feasible method used for CTC identification but needs standardized protocol and trained technician in order to be widely used.
Abbreviations
CRC- colorectal cancer
CTC- circulating tumor cells
OS- overall survival
DFS- disease free survival
RT-PCR- reverse transcription polymerase chain reaction
EpCAM- epithelial cells adhesion molecule

\section{Acknowledgement}

This scientific report in finance by the University of Medicine and Pharmacy Grigore T. Popa Iasi, based on the contract nr. 29028 / 28.12.2016.

\section{Conflict of interest}

The authors declare no conflict of interest.

\section{Reference}

1. Torino F, Bonmassar E, Bonmassar L, Vecchis L De, Barnabei A, Zuppi C, et al. Circulating tumor cells in colorectal cancer patients. Cancer Treat Rev. 2013;39(7):759-72. DOI: 10.1016/j.ctrv.2012.12.007

2. Dalum G Van, Stam G, Scholten LFA, Mastboom WJB. Importance of circulating tumor cells in newly diagnosed colorectal cancer. Int J Oncol. 2015;46:1361-8. DOI: 10.3892/ijo.2015.2824

3. Maestro LM, Sastre J, Rafael SB, Veganzones SB, Vidaurreta M, Martín M, et al. Circulating Tumor Cells in Solid Tumor in Metastatic and Localized Stages. 2009;4844:4839-43.

4. Venesio T, Siravegna G, Bardelli A, Sapino A. Liquid Biopsies for Monitoring Temporal Genomic Heterogeneity in Breast and Colon Cancers. Pathobiology. 2018;85(1-2):146-54. DOI: 10.1159/000473882

5. Sundling KE, Lowe AC. Circulating Tumor Cells : Overview and Opportunities in Cytology. Adv Anat Pathol. 2019 Jan;26(1):56-63.2019;26(1):56-63. DOI: 10.1097/PAP.0000000000000217

6. Katsuno H, Zacharakis E, Aziz O, Ziprin P, Athanasiou T, Darzi A. Does the Presence of Circulating Tumor Cells in the Venous Drainage of Curative Colorectal Cancer Resections Determine Prognosis? A Meta-Analysis. Ann Surg Oncol. 2008;15(11):3083-91. DOI: $10.1245 /$ s10434-008-0131-8

7. Rahbari NN, Aigner M, Thorlund K, Mollberg N, Motschall E, Jensen K, et al. Meta-analysis Shows That Detection of Circulating Tumor Cells Indicates Poor Prognosis in Patients With Colorectal Cancer. Gastroenterology. 2010;138(5):1714-26. DOI: 10.1053/j.gastro.2010.01.008

8. Lu Y, Wang P, Peng J, Wang X, Zhu Y, Shen N. Meta-analysis Reveals the Prognostic Value of Circulating Tumour Cells Detected in the Peripheral Blood in Patients with Non-Metastatic Colorectal Cancer. Sci Rep. 2017 Apr 19;7(1):905. DOI: 10.1038/s41598-01701066-y

9. Tan $\mathrm{Y}, \mathrm{Wu} \mathrm{H}$. The significant prognostic value of circulating tumor cells in colorectal cancer: A systematic review and meta-analysis. Curr Probl Cancer. 2018 Jan-Feb;42(1):95-106. DOI: 10.1016/j.currproblcancer.2017.11.002

10. Sastre J, Maestro ML, Puente J, Veganzones S, Alfonso $\mathrm{R}$, Rafael S, et al. Circulating tumor cells in colorec- 
tal cancer: correlation with clinical and pathological variables. Ann Oncol. 2008 May;19(5):935-8. DOI: 10.1093/annonc/mdm583

11. Peach G, Kim C, Zacharakis E, Purkayastha S, Ziprin P. Prognostic significance of circulating tumour cells following surgical resection of colorectal cancers: a systematic review. Br J Cancer. 2010;102(9):1327-34. DOI: 10.1038/sj.bjc.6605651

12. Sales J, Wind P, Douard R. Blood dissemination of colonic epithelial cells during no-touch surgery for rectosigmoid cancer. Lancet. 1999 Jul 31;354(9176):392. DOI: 10.1016/S0140-6736(99)92164-5

13. Chen WS, Chung MY, Liu JH, Liu JM, Lin JK. Impact of circulating free tumor cells in the peripheral blood of colorectal cancer patients during laparoscopic surgery. World J Surg. 2004;28(6):552-7. DOI: 10.1007/ s00268-004-7276-9

14. Ramdane Harouakaa, Zhigang Kangb, Siyang Zhenga and LC. Circulating tumor cells: advances in isolation and analysis, and challenges for clinical applications. Pharmacol Ther. 2014 Feb; 141(2): 209-221. DOI: 10.1016/j.pharmthera.2013.10.004

15. Vaiopoulos AG, Kostakis ID, Gkioka E, Christopoulos P, Gogas H, Kouraklis G, et al. Detection of Circulating Tumor Cells in Colorectal and Gastric Cancer Using a Multiplex PCR Assay. Anticancer research. 2014;34(6):3083-92.

16. Assay T, Luca A De, Pignata S, Casamassimi A, Antonio AD, Gridelli C, et al. Detection of Circulating Tumor Cells in Carcinoma Patients by a Novel Epidermal Growth Factor Receptor Reverse. Clin Cancer Res. 2000;6:1439-44.

17. Thorsteinsson M, Jess P. The clinical significance of circulating tumor cells in non-metastatic colorectal cancer e A review. Eur J Surg Oncol. 2011;37(6):459-65. DOI: 10.1016/j.ejso.2011.01.025

18. Huang X, Gao P, Song Y, Sun J, Chen X, Zhao J, et al. Meta-analysis of the prognostic value of circulating tumor cells detected with the CellSearch System in colorectal cancer. BMC Cancer. 2015;15:202. DOI: 10.1186/s12885-015-1218-9

19. Mund JA, Estes ML, Yoder MC, Ingram DA Jr, Case J. Flow cytometric identification and functional characterization of immature and mature circulating endothelial cells. Arterioscler Thromb Vasc Biol. 2012;32(4):10451053. DOI: 10.1161/ATVBAHA.111.244210

20. Duda DG, Cohen KS, Scadden DT, Jain RK. A proto- col for phenotypic detection and numeration of circulating endothelial cells and circulating progenitor cells in human blood. Nat Protoc. 2007;2(4):805-10. DOI: 10.1038/nprot.2007.111

21. Huang X, Gao P, Song Y, Sun J, Chen X, Zhao J, et al. Relationship between circulating tumor cells and tumor response in colorectal cancer patients treated with chemotherapy: a meta-analysis. BMC Cancer. 2014;14:976. DOI: 10.1186/1471-2407-14-976

22. Sun W, Li G, Wan J, Zhu J, Shen W, Zhang Z. Circulating tumor cells : A promising marker of predicting tumor response in rectal cancer patients receiving neoadjuvant chemo- radiation therapy. Oncotarget. 2016;7(43):69507-17. DOI: 10.18632/oncotarget. 10875

23. Bünger S, Zimmermann M, Habermann JK. Diversity of assessing circulating tumor cells (CTCs ) emphasizes need for standardization: a CTC Guide to design and report trials. Cancer Metastasis Rev. 2015;34(3):52745. DOI: $10.1007 / \mathrm{s} 10555-015-9582-0$

24. Moher D, Liberati A, Tetzlaff J, Altman DG. Preferred reporting items for systematic reviews and meta-analyses: The PRISMA statement. BMJ. 2009;339(7716):332-6. DOI: 10.1136/bmj.b2535

25. Fang C, Fan C, Wang C, Huang Q, Meng W, Yu Y, et al. Prognostic value of CD133+ CD54+ CD44+ circulating tumor cells in colorectal cancer with liver metastasis. Cancer Med. 2017;6(12):2850-57. DOI: 10.1002/ cam4.1241

26. Galizia G, Gemei M, Orditura M, Romano C, Zamboli A, Castellano P, et al. Postoperative Detection of Circulating Tumor Cells Predicts Tumor Recurrence in Colorectal Cancer Patients. J Gastrointest Surg. 2013;17(10):1809-18. DOI: 10.1007/s11605-0132258-6

27. Tralhao, J.G Hoti, E, Serdio, M Laranjeiro P, Paiva A, Abrantes AM, Hoti E, Sero M. Perioperative tumor cell dissemination in patients with primary or metastatic colorectal cancer. Eur J Surg Oncol. 2010;36(2):125-9. DOI: 10.1016/j.ejso.2009.07.003

28. Cohen SJ, Alpaugh RK, Gross S, Hara SMO, Smirnov DA, Terstappen LWMM, et al. Isolation and Characterization of Circulating Tumor Cells in Patients with Metastatic Colorectal Cancer. Clin Colorectal Cancer. 2006;6(2):125-32. DOI: 10.3816/CCC.2006.n.029

29. Tseng J, Yang C, Liang S, Liu R, Yang S, Lin J. Interleukin-17A Modulates Circulating Tumor Cells in Tu- 
mor Draining Vein of Colorectal Cancers and Affects Metastases. Clin Cancer Res. 2014;20(11):2885-97. DOI: 10.1158/1078-0432.CCR-13-2162

30. Tsavellas G, Huang A, Mccullough T, Patel H, Araia R. Flow cytometry correlates with RT-PCR for detection of spiked but not circulating colorectal cancer cells. Clin Exp Metastasis. 2002;19(6):495-502. DOI: 10.1023/A:1020350117292

31. Bahnassy AA, Salem SE, Mohanad M, Abulezz NZ, Abdellateif MS, Hussein M, et al. Prognostic significance of circulating tumor cells (CTCs) in Egyptian non- metastatic colorectal cancer patients: A comparative study for four di ff erent techniques of detection (Flowcytometry, CellSearch, Quantitative Real-time PCR and Cytomorpholoqy). Exp Mol Pathol. 2019;106:90-101. DOI: 10.1016/j.yexmp.2018.12.006

32. Aghagolzadeh P, Radpour R. New trends in molecular and cellular biomarker discovery for colorectal cancer. World J Gastroenterol. 2016;22(25):5678-93. DOI: 10.3748/wjg.v22.i25.5678

33. Denis JA, Lacorte J-M. Detection of RAS mutations in circulating tumor cells: applications in colorectal cancer and prospects. Ann Biol Clin (Paris). 2017;75(6):60718. DOI: 10.1684/abc.2017.1304

34. Tsavellas G, Patel H, Allen-Mersh TG. Detection and clinical significance of occult tumour cells in colorectal cancer. Br J Surg. 2001;88(10):1307-20. DOI: 10.1046/j.0007-1323.2001.01863.x

35. Wang L, Wang Y, Liu Y, Cheng M, Wu X, Wei H. Flow cytometric analysis of CK19 expression in the peripheral blood of breast carcinoma patients: relevance for circulating tumor cell detection. J Exp Clin Cancer Res. 2009;28(1):57. DOI: 10.1186/1756-9966-28-57

36. Lopez A, Harada K, Mizrak Kaya D, Dong X, Song S, Ajani JA. Liquid biopsies in gastrointestinal malignancies: when is the big day? Expert Rev Anticancer Ther. 2018;18(1):19-38. DOI: 10.1080/14737140.2018.1403320

37. Malara N, Trunzo V, Foresta U, Amodio N, Vitis S De, Roveda L. Ex vivo characterization of circulating colon cancer cells distinguished in stem and differentiated subset provides useful biomarker for personalized metastatic risk assessment. J Transl Med. 2016;14(1):133. DOI: 10.1186/s12967-016-0876-y

38. Vlems FA, Diepstra JHS, Cornelissen IMHA, Ruers TJM, Ligtenberg MJL, Punt CJA, et al. Limitations of cytokeratin 20 RT-PCR to detect disseminated tumour cells in blood and bone marrow of patients with colorectal cancer: expression in controls and downregulation in tumour tissue. J Clin Pathol - Mol Pathol. 2002;55(3):156-63. DOI: 10.1136/mp.55.3.156

39. Søreide K, Watson MM, Lea D, Nordgård O, Søreide JA, Hagland HR. Assessment of clinically related outcomes and biomarker analysis for translational integration in colorectal cancer (ACROBATICC): Study protocol for a population-based, consecutive cohort of surgically treated colorectal cancers and resected colorectal liver metastasis. J Transl Med. 2016;14(1):192. DOI: 10.1186/s12967-016-0951-4

40. Chou WC, Wu MH, Chang PH, Hsu HC, Chang GJ, Huang WK, et al. A prognostic model based on circulating tumour cells is useful for identifying the poorest survival outcome in patients with metastatic colorectal cancer. Int J Biol Sci. 2018;14(2):137-46. DOI: 10.7150/ijbs. 23182

41. Connor AA, McNamara K, Al-Sukhni E, Diskin J, Chan D, Ash C, et al. Central, But Not Peripheral, Circulating Tumor Cells are Prognostic in Patients Undergoing Resection of Colorectal Cancer Liver Metastases. Ann Surg Oncol. 2016;23(7):2168-75. DOI: 10.1245/ s10434-015-5038-6

42. Rahbari NN, Bork U, Kircher A, Nimitz T, Schölch S, Kahlert C, et al. Compartmental differences of circulating tumor cells in colorectal cancer. Ann Surg Oncol. 2012;19(7):2195-202. DOI: 10.1245/s10434-0112178-1

43. Gogenur M, Hillig T, Gogenur I. CytoTrack analysis reveals low presence of circulating tumor cells in the perioperative period in patients with non-metastatic colorectal cancer. Anticancer Res. 2017;37(6):3099103. DOI: 10.21873 /anticanres. 11666

44. Tsai WS, Chen JS, Shao HJ, Wu JC, Lai JM, Lu SH, et al. Circulating Tumor Cell Count Correlates with Colorectal Neoplasm Progression and Is a Prognostic Marker for Distant Metastasis in Non-Metastatic Patients. Sci Rep. 2016;6(3):4-11. DOI: 10.1038/ srep 24517

45. Wu W, Zhang Z, Gao XH, Shen Z, Jing Y, Lu H, et al. Clinical significance of detecting circulating tumor cells in colorectal cancer using subtraction enrichment and immunostainingfluorescence in situ hybridization (SE-iFISH). Oncotarget. 2017;8(13):21639-49. DOI: 10.18632 /oncotarget. 15452 
46. Bosch B, Guller U, Schnider A, Maurer R, Harder F, Metzger U, et al. Perioperative detection of disseminated tumour cells is an independent prognostic factor in patients with colorectal cancer. Br J Surg. 2003;90(7):882-8. DOI: 10.1002/bjs.4129

47. Seeberg LT, Brunborg C, Waage A, Hugenschmidt H, Renolen A, Stav I, et al. Survival Impact of Primary Tumor Lymph Node Status and Circulating Tumor Cells in Patients with Colorectal Liver Metastases. Ann Surg Oncol. 2017;24(8):2113-21. DOI: 10.1245/s10434$017-5818-2$

48. Wind J, Tuynman JB, Tibbe AGJ, Swennenhuis JF, Richel DJ. Circulating tumour cells during laparoscopic and open surgery for primary colonic cancer in portal and peripheral blood. Eur J Surg Oncol. 2009;35(9):942-50. DOI: 10.1016/j.ejso.2008.12.003
49. Abalde-cela S, Piairo P. The Significance of Circulating Tumour Cells in the Clinic. Acta Cytol. 2019:1-13. DOI: $10.1159 / 000495417$

50. Schmidt T, Koch M, Antolovic D, Reissfelder C, Schmitz-winnenthal FH, Rahbari NN, et al. Influence of two different resection techniques (conventional liver resection versus anterior approach) of liver metastases from colorectal cancer on hematogenous tumor cell dissemination - prospective randomized multicenter trial. BMC Surg. 2008;8:6. DOI: 10.1186/1471-2482-8-6

51. Groot Koerkamp B, Rahbari NN, Büchler MW, Koch M, Weitz J. Circulating tumor cells and prognosis of patients with resectable colorectal liver metastases or widespread metastatic colorectal cancer: A meta-analysis. Ann Surg Oncol. 2013;20(7):2156-65. DOI: 10.1245/s10434-013-2907-8 